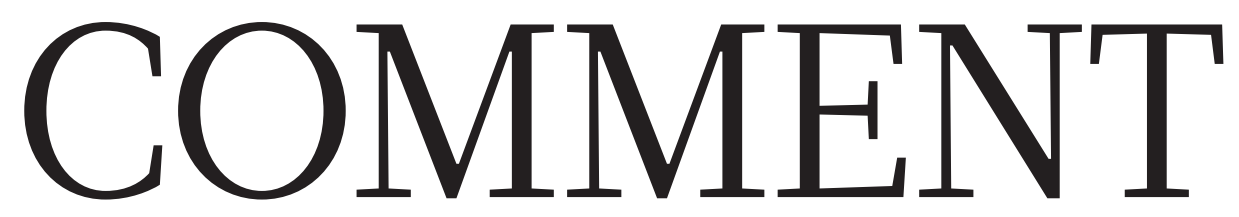

GEOLOGY LOng line of triumph and failure - the hunt for Earth's magnetic heart p.28
NEUROSCIENCE Antonio

Damasio's argument for emotions, appraised p.30
PUBLIC HEALTH Study

the risk of yellow fever in Asia-Pacific p.31
PSYCHIATRY Pamela Sklar, pioneer of mental-health genomics, remembered $\mathbf{p . 3 2}$

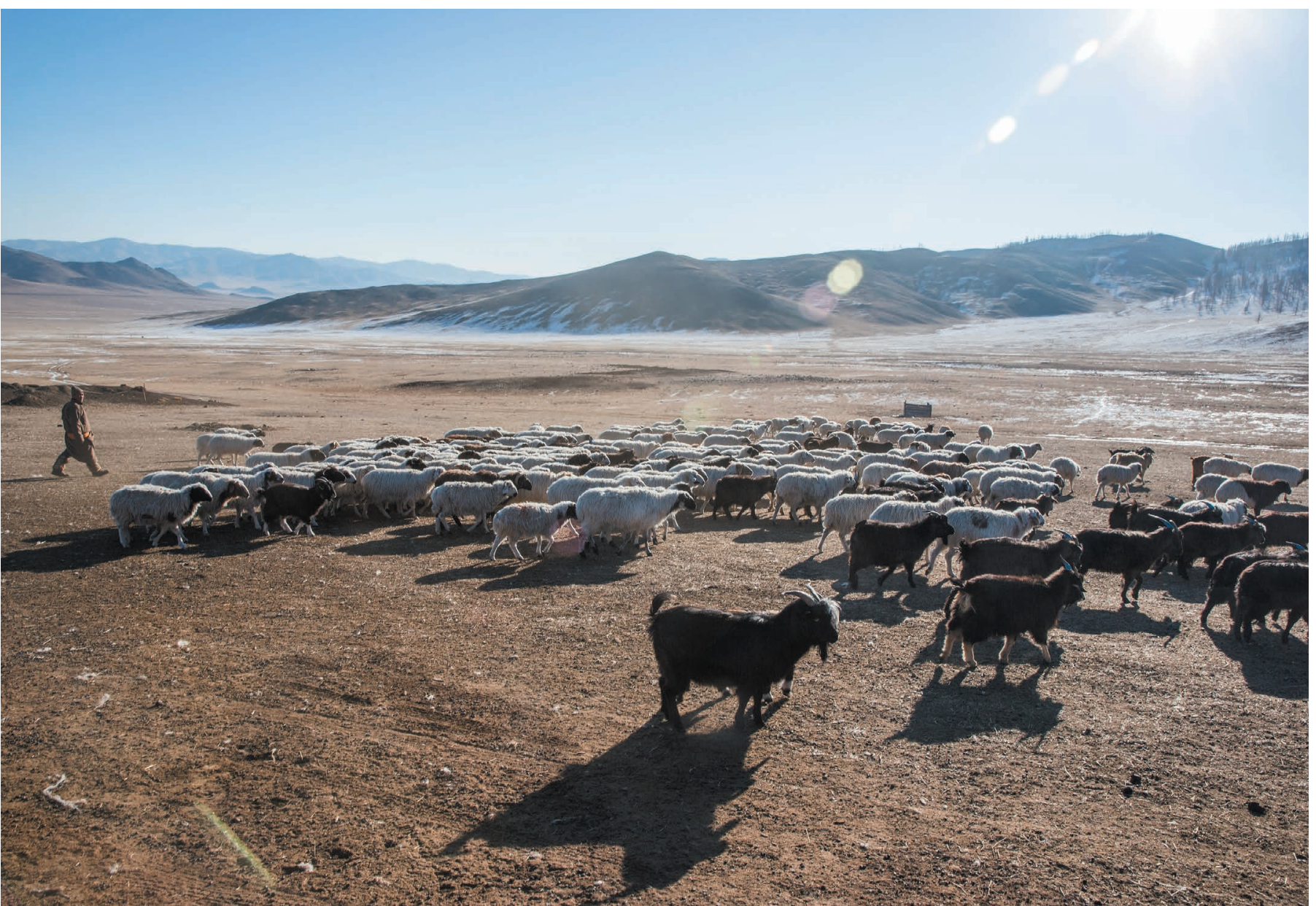

Many developing countries, such as Mongolia, have rural economies, so projects that can provide farmers with up-to-date agricultural information are crucial.

\title{
Steps to the digital Silk Road
}

Sharing big data from satellite imagery and other Earth observations across Asia, the Middle East and east Africa is key to sustainability, urges Guo Huadong.

$\mathrm{T}$ The ancient Silk Road trade routes connecting Asia, Europe and Africa lay behind the development of many great civilizations. Today, solar panels and smartphones have replaced silk, and trains and aeroplanes have superseded camels. But the Silk Road spirit of peace, mutual benefit and learning has been revived in an ambitious plan to bridge East and West, launched in 2013 by Chinese President Xi Jinping.
The 'Belt and Road' initiative promises more than US\$1 trillion of Chinese investment in some 60 countries (see 'Belt and Road'). All other nations are welcome to join in. The main aim is socio-economic development through improving the routes for land and sea trade. The initiative will also boost science and technology across the region, for example through research into artificial intelligence, nanotechnology, quantum computing and smart cities (see go.nature.com/2mvfec6).

But protecting the environment while supporting economic growth will be challenging. The Belt and Road region is home to more than $65 \%$ of the world's population. It includes 18 cities that have populations of greater than 10 million, such as Beijing, Cairo, Moscow, Manila and Istanbul.

Environments are diverse and fragile. 
> Conditions range from the snow, ice and permafrost of the Qinghai-Tibet Plateau to the forests and steppes of Russia and the deserts of Mongolia. Coasts and seas are threatened by rising sea levels, overfishing and pollution. Access to water is a big problem across central Asia. For example, the volume of water in the Aral Sea has shrunk by around $90 \%$ in the past 50 years, mainly because the sea and its rivers have been tapped for irrigation.

World Heritage Sites designated by the United Nations Educational, Scientific and Cultural Organization (UNESCO) are endangered by construction, logging, overexploitation and climate change. These include Sumatra's tropical rainforests; Uzbekistan's historic centre of Shakhrisyabz; and the world's secondlargest raised coral atoll, in the Solomon Islands at the eastern end of Rennell Island.

The economies of many developing countries are rural, with agriculture accounting for more than $25 \%$ of gross domestic product. Often, more than $40 \%$ of a developing country's workforce is involved in farming. Food supplies can be unreliable.

Natural hazards are another threat. Belt and Road nations experience about $85 \%$ of the world's major earthquakes, tsunamis, typhoons, floods, droughts and heatwaves. For example, more than 86,000 people were killed or reported as missing in a massive earthquake in Wenchuan, China, in May 2008. And the 2004 Indian Ocean earthquake and tsunami killed hundreds of thousands of people. Seven of the top ten countries that saw major losses from disasters between 1995 and 2014 are in this region.

If we do nothing, sensitive environments will be lost and exposure to risks will rise.

To address these problems, a combination of accurate, reliable and timely scientific observations of the state of terrestrial and marine ecosystems is essential - from space, the air and on the ground. However, coverage and infrastructure are poor. Many countries cannot afford to train experts in Earth-observing techniques or install ground stations to monitor soil nutrients or air quality. For example, Kyrgyzstan, Tajikistan, Turkmenistan and Uzbekistan have no Earth-observing satellites or facilities for mass data processing. Local data are rarely shared and are often locked away in government or university archives.

I chair the Digital Belt and Road Program (DBAR) initiated in 2016 by Chinese scientists in cooperation with experts from 19 countries and 7 international organizations. Our aim is to improve environmental monitoring, promote data sharing and support policymaking using big data on Earth observations. The Chinese Academy of Sciences (CAS) is investing more than
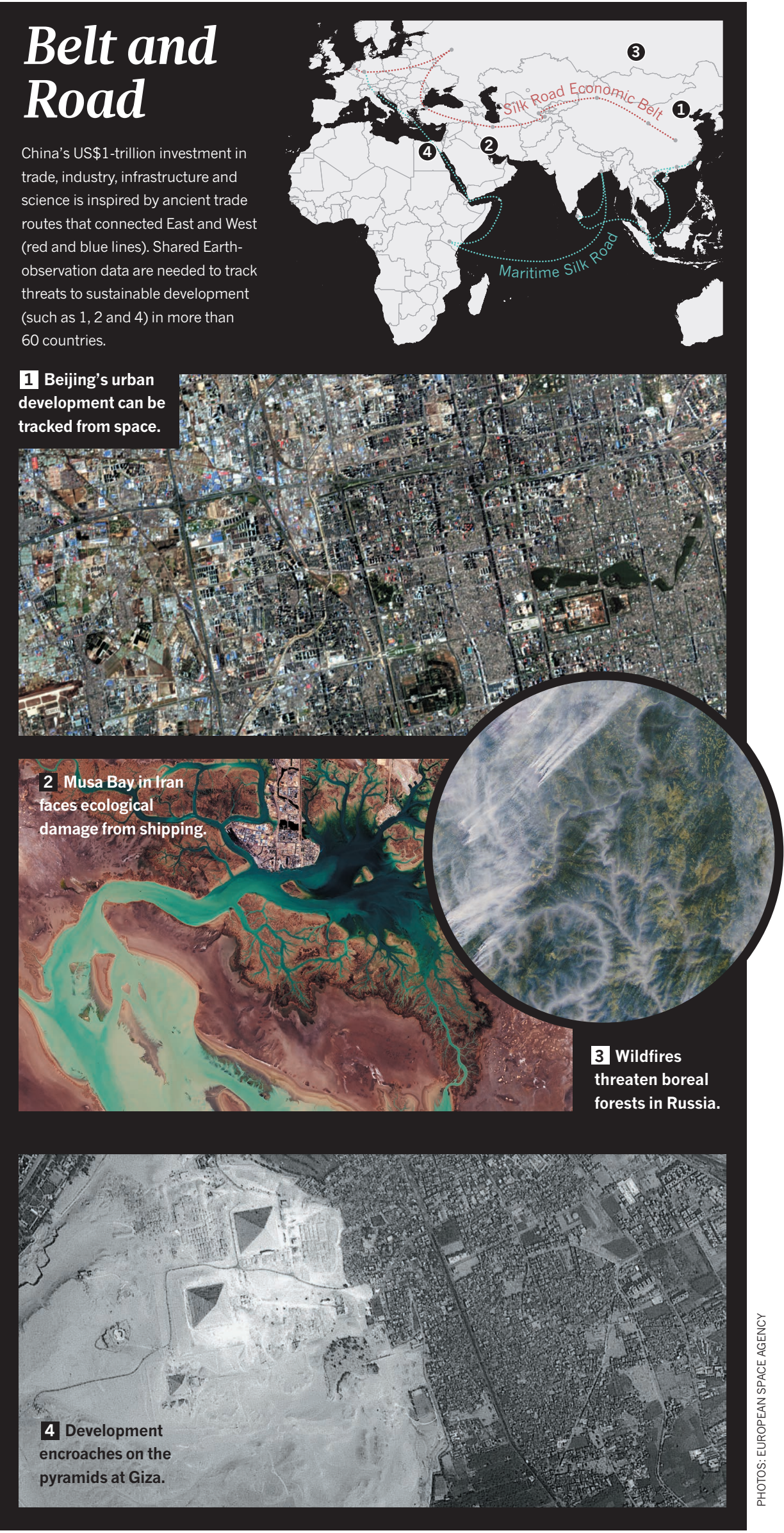
200 million yuan (US\$32 million) in the next 5 years to support DBAR.

The programme will monitor different types of ecosystem and their evolution, including grasslands, forests, glaciers, urban areas, farmland and coastal regions. Environmental and socio-economic information will be shared through a platform for big Earth data, scheduled for roll-out between 2016 and 2026. This open-access gateway will allow researchers, policymakers and the public to track changes, development and trends. The programme will investigate indices and indicators to feed into the UN's 2030 Sustainable Development Goals.

Here we set out the main scientific challenges and priorities for DBAR. These were presented and discussed in December 2017 at the second DBAR conference in Hong Kong ${ }^{1}$.

\section{PROOF OF CONCEPT}

There are four main obstacles to a strategy on big Earth data for the Belt and Road region: poor access to data; a digital divide between developed and developing countries; a lack of awareness among some policymakers, local scientists and practitioners of the potential of Earth observations; and too little collaboration. These are long-standing problems - they also slowed emergency responses during and after the Indian Ocean tsunami in 2004, for example.

DBAR's main approach is to work towards a platform that can handle a wide variety of information. Data sets and infrastructure are being assembled, and services should start to become available by the end of 2018. Eight key challenges are being targeted: adapting to climate and environmental change; mitigating disaster risk; managing water supplies; increasing agriculture and food security; protecting natural and cultural heritage; sustainable development of urban areas and infrastructure; managing coasts and marine areas; and understanding changes in high mountains and the Arctic.

For example, in agriculture, the main difficulty faced by most food-insecure countries of the region is a lack of up-to-date information about the supplies, yields and management of crops. DBAR is expanding the cloud-computing-based system CropWatch for monitoring and managing the availability of maize (corn), rice, wheat and soya-bean products. Launched by CAS in 1998, CropWatch provides users from 143 countries or regions with easy access to agricultural information.

For disaster relief and risk reduction, DBAR is developing a platform for sharing Earth-observation imagery. The value of such information in quickly assessing the impacts of extreme events has been proved in China and developed countries, and needs to be opened to others. For example, following the 2008 Wenchuan earthquake, Chinese rescuers were alerted to 700 people trapped in a village after seeing aerial imagery of "SOS700" written on top of a building.

The processes that shape urbanization need to be understood. Earth observations can reveal trends in the growth of cities and help planners to overcome traffic congestion, energy shortages, urban sprawl and poor basic services. For example, DBAR scientists are modelling the growth of Moscow to inform development in Beijing. The programme is also monitoring the impacts of some big infrastructure projects, including the Mombasa-Nairobi Standard Gauge Railway, Colombo Port City and the Malaysia-China Kuantan Industrial Park.

The entire landscapes of World Heritage Sites including human influences - need to be protected, not just their monuments ${ }^{2}$. For example, "If we do
nothing,
sensitive
environments
will be lost and
exposure to
risks will rise." at Angkor in Cam-

bodia, Earth observations that included airborne laser scans revealed the remains of multiple cities aged 900 to 1,400 years old lying beneath the tropical forest floor ${ }^{3}$. Deforestation and urban sprawl are the main risks that should inform a broader management strategy.

\section{WAY FORWARD}

We plan to focus on five priority areas at DBAR.

Enhance infrastructure. An open platform with shared data, codes and algorithms is urgently needed for analysing the vast amounts of Earth-observation data, which are already daunting and will only increase. The European Space Agency's Sentinel-5P satellite, launched in October 2017, takes 20 million observations of air pollutants and gases each day -10 times more than previous missions. Cloud computing must therefore be core ${ }^{4}$. It would currently take 1,200 years for one computer to process 3 million planetary-scale satellite scenes; a cloud-computing facility could do it in 45 days $^{5}$. Earth-observing satellite data from upcoming missions will need to be incorporated.

Promote data sharing and interoperability. Data need to be openly exchanged if everyone in the region is to benefit. This will require decisions about suitable formats, information and support for handling them, as well as methodologies and tools to maximize exploitation of the data.

Extend applications to more people. Development across the Belt and Road region is uneven. To close these gaps, it is necessary to improve common solutions provided by big Earth data ${ }^{6}$. Access to tools such as CropWatch needs to be extended. Use of the digital cloud can allow anyone to access services anywhere across the region, and to accelerate the development of applications for various users.

Identify research opportunities. Knowledge could be discovered within the huge multidisciplinary data sets. For example, studying changes in the land surface of the Yellow River Delta from space over the past 40 years has increased our understanding of how its evolution depends on land use, precipitation and water flows. Researchers must help to raise awareness of the scientific potential and solutions provided by big Earth data, especially in less-developed countries.

Strengthen international collaboration. Belt and Road nations should set up bilateral or multilateral arrangements and stronger links with international scientific programmes and organizations. These include UNESCO, the UN Environment Programme, the UN Office for Disaster Risk Reduction, the Committee on Data for Science and Technology, the Pan-Eurasian Experiment and the Group on Earth Observations.

To help bridge the technical divides between richer and poorer nations, DBAR should set up joint programmes, laboratories and international centres of excellence for gathering experts from participating countries. The programme has already established eight centres of excellence, in Pakistan, Thailand, Finland, Italy, Russia, Morocco, Zambia and the United States.

DBAR has embarked on an ambitious journey to build a digital Silk Road for sustainable development - we invite even more natural and social scientists to join this shared endeavour.

Guo Huadong is chair of DBAR; a professor of remote-sensing science at the Institute of Remote Sensing and Digital Earth, Chinese Academy of Sciences, Beijing, China; president of the International Society for Digital Earth; and former president of the ICSU Committee on Data for Science and Technology. e-mail:hdguo@radi.ac.cn

1. Digital Belt and Road Program (DBAR). DBAR Science Plan: An International Science Program for Sustainable Development of the Belt and Road Region Using Big Earth Data (DBAR, 2017); available at http://go.nature.com/2evoxcj

2. Chen, F. L. et al. Sci. Adv. 3, e1601284 (2017).

3. Evans, D. J. Archaeol. Sci. 74, 164-175 (2016).

4. Hansen, M. C. et al. Science 342, 850-853 (2013).

5. Pekel, J-F., Cottam, A., Gorelick, N. \& Belward, A. S. Nature 540, 418-422 (2016).

6. Guo, H. Big Earth Data 1, 4-20 (2017). 